\title{
Tribological Effects of Mineral-Oil Lubricant Contamination with Biofuels: A Pin-on-Disk Tribometry and Wear Study
}

\author{
S. M. Shanta, G. J. Molina, and V. Soloiu \\ Department of Mechanical and Electrical Engineering, Georgia Southern University, Statesboro, GA 30460-8045, USA \\ Correspondence should be addressed to G. J. Molina, gmolina@georgiasouthern.edu
}

Received 29 June 2011; Accepted 6 September 2011

Academic Editor: Dae Eun Kim

Copyright () 2011 S. M. Shanta et al. This is an open access article distributed under the Creative Commons Attribution License, which permits unrestricted use, distribution, and reproduction in any medium, provided the original work is properly cited.

Use of biodiesel produces engine oil dilution because of unburned biodiesel impinging on cold walls of the combustion chamber, being scrapped to the oil pan, and leading to changes of oil friction, wear and lubricity properties. In this paper, mixtures of SAE 15W-40 oil, which were contaminated by known percentages of the biodiesels from canola oil, peanut oil, soybean oil, and chicken fat, were tested in a pin-on-disk tribometer. A contact was employed of AISI 1018 steel disk and AISI 316 stainless-steel ball for pin material, and friction force and specific wear were measured. Wear on the disk surfaces showed that any degree of mineraloil dilution by the tested biodiesels reduces the wear protection of engine oil even at small mixture percentages. However, these reductions were not substantially different than those observed for same percentages of dilution of mineral oil by fossil diesel. The tested mixture of oil contaminated with animal fat feedstock (e.g., chicken fat) biodiesel showed the best wear behavior as compared to those for the other tested mixtures (of mineral oil with vegetable feedstock biodiesel dilutions). Obtained results are discussed as baseline for further studies in a renewable energy multidisciplinary approach on biofuels and biolubes.

\section{Introduction}

Biofuels are an important source of renewable and sustainable energy. Biodiesel is produced from feedstock oils through the reaction known as transesterification, where one mole of triglyceride reacts with three moles of alcohol to form one mole of glycerol and three moles of the respective fatty acid alkyl esters [1]. During cold start-up and stop-andgo regimes in a internal combustion, the nonvaporized fuel condensed on the liner is scrapped by the piston rings and reaches the oil pan where it dilutes the lubricating oil. Some limited engine oil dilution by diesel engine fuel is acceptable and it happens in all diesel engines. But when the engine is fueled by biodiesel or biodiesel blends, engine oil dilution rates and their effects can be different than those from regular diesel fuel. Gili et al. [2] discussed two main reasons that are responsible for the different biodiesel dilution in engine oil: (i) that biodiesel tends to accumulate in the engine oil because of its lower distillation temperature, leading to more unburned biodiesel dilution in the engine oil, and (ii) that diesel fuels have different solvencies properties than esterfluids biodiesels.
Wear properties of biodiesels have been recently studied using different tribometer techniques by Fang et al. [3]. They tested the effect of pure biodiesel fuel (B100) on the wear characteristics of a biodiesel-contaminated oil by using the tribometer methods of electrical contact resistance, high frequency reciprocating rig (HFRR) and four-ball testing. They consistently found that while fresh biodiesel might actually decrease wear, aged-biodiesel degradation products can interact with additives, mainly with Zinc dialkyldithiophosphates (ZDDP), and that excessive fuel dilution in engine oil can lead to complex formation between oxidized biodiesel components and ZDDP. They also reported that lube oil dilution with aged biodiesel may increase wear even at concentrations of $5 \%$ or less, and that severe impact of aged biodiesel was likely caused by interactions between ZDDP and the partially oxidized biodiesel.

Sulek at al. [4] carried out an assessment of some tribological properties for the mixture of diesel fuel and biodiesel derived from rapeseed oil. That study was carried out for steel-steel pairs with an HFRR tribometer. They found that a $5 \%$ of the tested rapeseed methyl ester in fossil diesel-fuel reduced friction force by $20 \%$, and that rapeseed 
B100 produced a 30\% lower friction coefficient than that of $100 \%$ fossil fuel. Jech et al. [5], of $\mathrm{AC}^{2} \mathrm{~T}$ Research $\mathrm{GmbH}$ and Vienna University of Technology, used a model tribometer based on nanoscale wear volume coherence (nVCT) to investigate the lubricity effects (e.g., volumetric wear) of biodiesel dilutions. They found that biodiesel concentrations of about $10 \%$ in fossil oil slightly increased wear, but higher concentrations (from $30 \%$ and up) induced lower progressive wear. These previous works on the tribology of biodiesel mixtures with mineral-oil and fossil diesels indicate that tribological properties of such mixtures can be substantially different than those for conventional fossil mineral oil and suggest that contamination by biodiesel in fossil oil can affect the lubricity of such mixture. But that the impact of biodiesels (and of their mixtures and blends with fossil oils) on engine tribology is not completely understood.

Some studies have investigated the physical and chemical properties for biodiesel in mineral oil mixtures, as they can affect engine performance and tribological behavior: Agarwal [6] reported that viscosity of the lubricating oil decreased with engine runtime mainly due to increasing fuel dilution by the biofuels. Thornton et al. [7] evaluated the biodiesel blend effects in oil dilution and on the associated engine performance. They concluded that biodiesel in the engine oil led to enhanced oxidation, which increased acidity and led to a reduction in TBN (total base number). Watson and Wong [8] later investigated dilution effects of soy-oil based methyl ester biodiesel (as they compare it with ultralow sulfur diesel fuel) on CI-4+ and CJ-4 lubricants. Using a bench scale oxidation test they found a substantial increase of the lubricant acidity with increasing dilution degrees of biodiesel in the CI-4+ and CJ-4 mineral oils.

While there is extensive experience on instrumentation of actual engines for friction and wear measurements, this methodology has been highly focused on technical problems rather than on fundamentals. Typical experimental research works would aim at solving a particular problem and for a given fuel, but they provide little basis for generalized science-base approaches. Some relevant works included setups to measure cam friction torque by a spring system which minimized friction between the tappet and the guide [9], and to assess valve-train friction by measuring driving torque while successively removing components [10]. Wakuri et al. [11] measured friction force on the tapped by strain gage techniques, and Choi et al. [12] used the electrical capacitance method on the cam-tappet contact to determine oil film thickness and friction force. Agarwal [6] presented the first known engine-wear-based investigation on oil contaminated by biofuels, but without evaluating energy losses or making comparisons of investigated to effective (e.g., for noncontamination) parameter values. He reported that viscosity of the lubricating oil decreased with engine runtime mainly due to increasing fuel dilution by the biofuels. By analysis of engine oil after tests with biodiesels, Bijwe et al. [13] found that pentane and benzene insolubles content reflected lower oil oxidation, and that ZDDP additive depletion was lower for the engine lubricating oil when fueled with biodiesel as compared to fossil diesel fuel; ferrograms revealed lower density and smaller size of wear debris (and suggested some corresponding lower wear of moving parts). In general, these experiments with biodieselfueled engine suggest that biodiesel mixing with oil may lead to enhanced lubricity of the mixture, because of inherent lubricity of the biofuel.

The literature review for this work revealed that there were only limited laboratory investigations on the wear and friction effects for typical engine material contacts when they are lubricated by biodiesel-contaminated mineral oils. No previous research work attempted comparisons of such wear and friction effects for different biodiesels; the authors hypothesized that the different fatty acid contents of typical biodiesels could lead to significant differences of wear behavior. The research work of this paper was carried out with the purpose of investigating several feedstock-produced biodiesels for their dilution effects on mineral engine oil, by assessing friction and wear in a pin-on-disk tribometer.

\section{Experimental Methods}

In this work biodiesels from four types of feedstock were tested, three of them obtained from vegetable feedstock (canola, peanut, and soybean oil biodiesels, produced in the Renewable Energy Laboratory of the Department of Electrical and Mechanical Engineering of Georgia Southern University) and the fourth one produced from an animal source (a chicken fat biodiesel, which was supplied by "Down to earth energy", a biodiesel producer in Georgia, USA).

Biodiesels from different feedstock typically contain different types and fractions of fatty acids. Table 1 presents the typical fatty acid contents $[14,15]$ for the four different biofuels tested in this work.

In this work, partially synthetic SAE $15 \mathrm{~W}-40$ Mobil Delvac Elite engine oil was used, with a $30 \%$ synthetic base stock. Table 2 presents the typical properties of the employed 15W-40 engine oil.

The employed tribometer was a T-11 pin-on-disk tribometer, adequate to perform ASTM G 99 standard wear and friction tests, designed and manufactured by the Institute for Sustainable Technologies, National Research Institute in Radom, Poland, and is presented in Figure 1. An additional NI9205 module (interfaced with LabVIEW software) was used to acquire data from the friction force transducer of the tribometer used in this work.

Material contact pair in this work consisted of a stationary AISI 316-stainless-steel bearing-grade ball of $3.175 \mathrm{~mm}$ (1/8 inch) diameter and an AISI 1018-25.4 mm diameter disk (of thickness $6 \pm 1 \mathrm{~mm}$ ). The material pair was chosen to obtain most of the significant wear for the softer AISI 1018 disk material, as compared to the harder AISI 316-stainlesssteel-ball pin; post test observations reasonably confirmed that test assumption. Since in this work contact materials and load, sliding speed and test duration, and environment parameters were kept unchanged, measured wear values can be attributed to lubricant properties and its surface interactions (e.g., mainly to the lubricant properties of the controlled biodiesel diluting engine oil mixtures) [17].

Disk surfaces were polished to mirror-like finishing by employing a sequence of $240,320,400$, and 600 grit sand 
TABLE 1: Typical fatty acid contents for the four different fuels tested in this work, from $[14,15]$.

\begin{tabular}{lcccc}
\hline Fatty acid & Chicken fat $(\%)$ & Soybean oil (\%) & Peanut oil (\%) & Canola oil (\%) \\
\hline Palmitic acid $16: 0$ & 25 & $6-10$ & $8-9$ & ND (no data) \\
Stearic acid $18: 0$ & 6 & $2-5$ & $2-3$ & 7 \\
Oleic acid $18: 1$ & 41 & $20-30$ & $50-65$ & 54 \\
Linoleic acid $18: 2$ & 18 & $50-60$ & $20-30$ & 30 \\
Linolenic acid $18: 3$ & ND & $5-11$ & ND & 7 \\
\hline
\end{tabular}

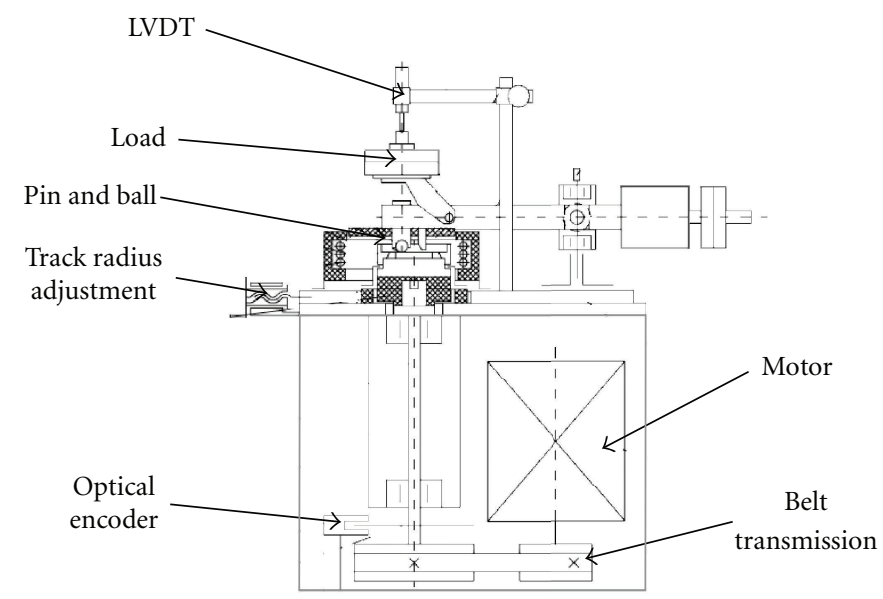

(a)

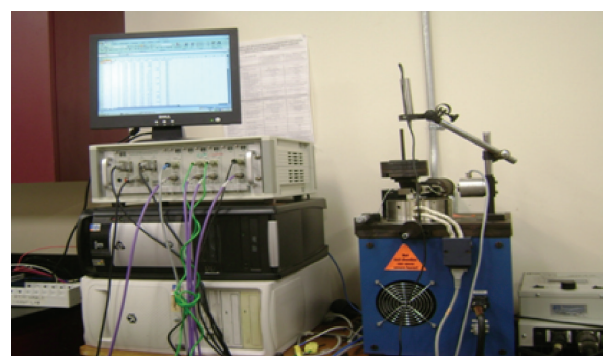

(b)

FIGURE 1: Schematics and photograph of pin-on-disk tribometer and experimental setup.

TABle 2: Properties of Mobil Delvac Elite 15W-40 oil, from [16].

\begin{tabular}{lcl}
\hline Properties & \multicolumn{1}{c}{ Method } & Base engine oil \\
\hline Viscosity, cst & ASTM D 445 & $\begin{array}{l}111 \mathrm{c} \text { at } 40^{\circ} \mathrm{C}, 15.2 \\
\text { at } 100^{\circ} \mathrm{C}\end{array}$ \\
$\begin{array}{l}\text { Viscosity index } \\
\text { Sulfated Ash, wt\% }\end{array}$ & ASTM D 2270 & 140 \\
Total base number, mg & ASTM D 2896 & 0.9 \\
KOH $/ g$ & ASTM D 97 & -36 \\
$\begin{array}{l}\text { Pour point, }{ }^{\circ} \mathrm{C} \\
\text { Flash point },{ }^{\circ} \mathrm{C}\end{array}$ & ASTM D 92 & 241 \\
Density at $15^{\circ} \mathrm{C} \mathrm{kg} / \mathrm{L}$ & ASTM D 4052 & 0.872 \\
\hline
\end{tabular}

paper to obtain a final roughness (Ra value) in the range of $1-10 \mu$ in (measured by a Mitutoyo SJ 210 instrument). A new disk and ball set was used in each experiment, and both disk and ball were previously cleaned in an ultrasonic bath using micro-90 cleaning solution in a 50:1 volume ratio. During the entire experiment, the room temperature was controlled between $17^{\circ} \mathrm{C}$ and $19^{\circ} \mathrm{C}$, and relative humidity was kept between $55 \%$ and $60 \%$. Relative sliding velocity of disk and ball was set at $0.15 \mathrm{~m} / \mathrm{s}$ for a total sliding distance of $1000 \mathrm{~m}$ for each of all carried out experiments. Applied normal load (pin load) was $19.2 \mathrm{~N}$ for all experiments.

Engine oil (15W-40) was diluted with known percentages of four different biodiesel produced from peanut oil (POB), canola oil (COB), soybean oil (SOB), and chicken fat (POB), and also with conventional fossil diesel, all five mixtures as compared to that of pure oil. Engine oil dilutions by each of these biodiesels and fossil diesel were mixed for four percentages of volume ratio dilutions: $5 \%, 10 \%, 20 \%$ and $30 \%$; the pure fossil oil (15W-40) also was tested under same conditions as reference.

In this work, the reported dimensional wear coefficient (or specific wear) values were calculated according to the classic Archard equation, where wear volume was measured by direct weight loss method of the tested disks, using a precision scale. Before and after experiments weight measurements were carried out, and the tested disk surfaces underwent ultrasonic cleaning in order to remove oils and external particulates (if any was present) from the worn surfaces. In process frictional force also was measured by the friction force transducer of the used tribometer.

\section{Results and Discussion}

3.1. Results for Mixtures of Canola Oil Biodiesel Diluted Mineral Oil. The employed engine oil (15W-40) was diluted with the canola oil biodiesel at 5\%, 10\%, 20\%, and 30\% volume ratios. Figure 2 presents specific wear measurements for these four mixtures and pure engine oil as reference. While pure engine mineral oil $(0 \%)$ shows the lowest wear for the tested conditions, for the 5\% and $10 \%$ dilutions wear is not substantially larger, but the $20 \%$ canola-oil-biodiesel mixture shows the maximum wear for the tested dilution interval. 


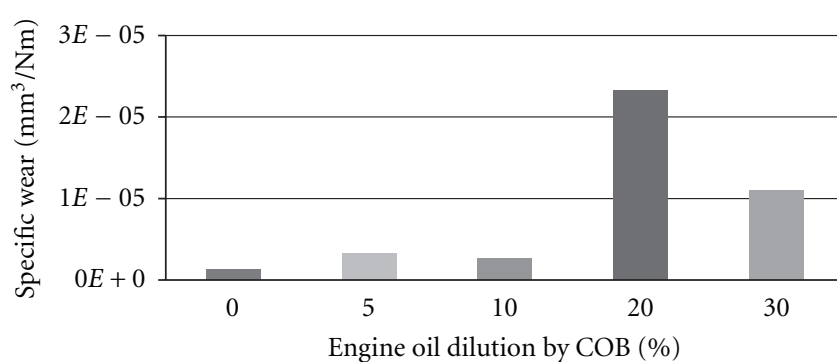

Figure 2: Specific wear for canola-oil biodiesel (COB) diluted engine oil mixtures.

The in-process friction force measurement is presented in Figure 3, which shows that friction force tends towards a constant value after a transient of less than 1,000 seconds. After that, and for all the four dilution percentages, frictional force did not significantly increased during test time. This indicates that no lubrication failure would have occurred in the $1000 \mathrm{~m}$ sliding distance contact (equivalent to 1 hour 51 minutes, or $6667 \mathrm{sec}$ ). But for all tested four dilution percentages it takes about 1,000 second to build up an adequate friction-reducing layer on the surface.

\subsection{Results for Mixtures of Peanut Oil Biodiesel Diluted Engine} Oil. The employed engine oil $(15 \mathrm{~W}-40)$ was diluted with the peanut oil biodiesel at 5\%,10\%,20\%, and $30 \%$ volume ratios. Figure 4 presents specific wear measurements for these four mixtures and pure engine oil as reference. While pure engine mineral oil $(0 \%)$ and $10 \%$ dilutions show the lowest wear values for the tested conditions, wear for the 5\% dilution is not substantially larger, but the $20 \%$ and $30 \%$ peanut-oil-biodiesel mixtures show similar maximum wear values for the tested dilution interval.

The in-process friction force measurement is presented in Figure 5, indicates that an anti-friction layer was developed on the surface in a short time (of less than $500 \mathrm{~s}$,) for $10 \%$, $20 \%$, and $30 \%$ peanut oil diluted engine oil mixtures, and from that time the friction force was measured seemingly constant during the duration of the experiment (equivalent to 1 hour 51 minutes, or 6667 seconds). For the 5\% dilution a small increment of friction force, but seemingly tending to a constant value, was observed in time after about $2000 \mathrm{~s}$.

3.3. Results for Mixtures of Soybean Oil Biodiesel Diluted Engine Oil. The employed engine oil $(15 \mathrm{~W}-40)$ was diluted with the soybean-oil biodiesel at 5\%,10\%, 20\%, and 30\% volume ratios. Figure 6 presents specific wear measurements for these four mixtures and pure engine oil as reference. While pure engine mineral oil (0\%) and 10\% dilution show the lowest wear values for the tested conditions, but the $20 \%$ and $30 \%$ soybean-oil-biodiesel mixtures shows similar maximum wear values for the tested dilution interval.

The in-process friction force measurements, which are presented in Figure 7, indicate that an anti-friction layer was fully developed on the surface (only after a transient time of about 3,000 seconds) for the 5\%, $10 \%$, and $20 \%$ mixtures, and from that time the friction force was about the

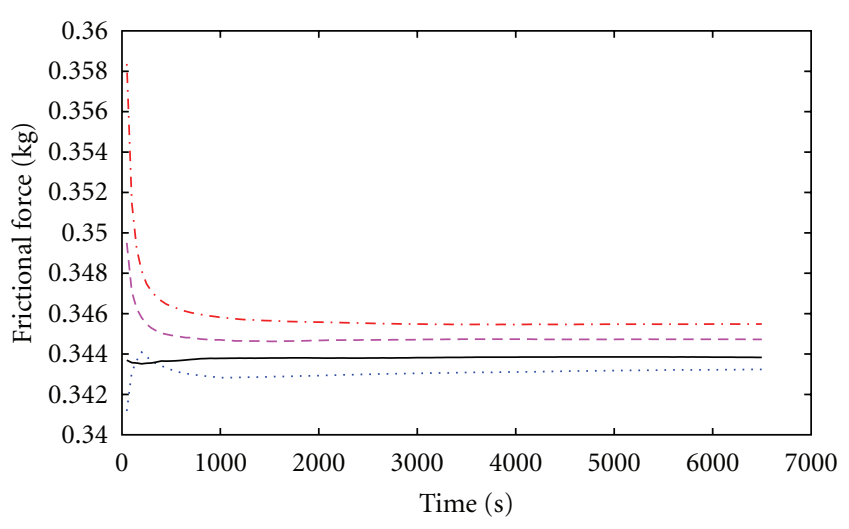

... $5 \%$ COB diluted engine oil

- - $10 \%$ COB diluted engine oil

… 20\% COB diluted engine oil

— $30 \%$ COB diluted engine oil

FIgURE 3: Friction force versus time for canola oil biodiesel and engine oil mixtures.

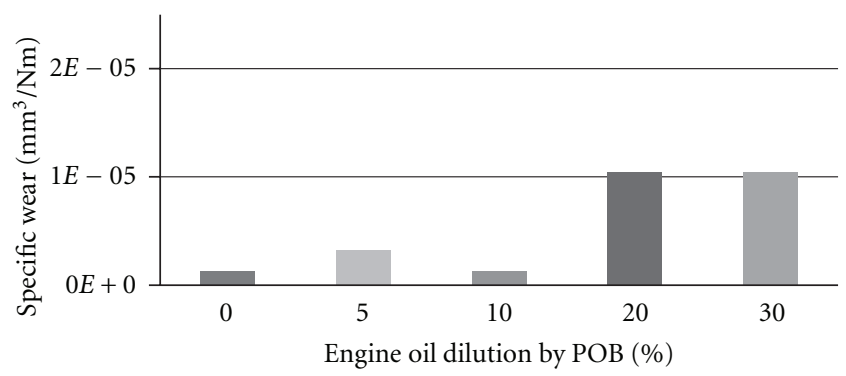

FIgURE 4: Specific wear for peanut oil biodiesel (POB) diluted engine oil mixtures.

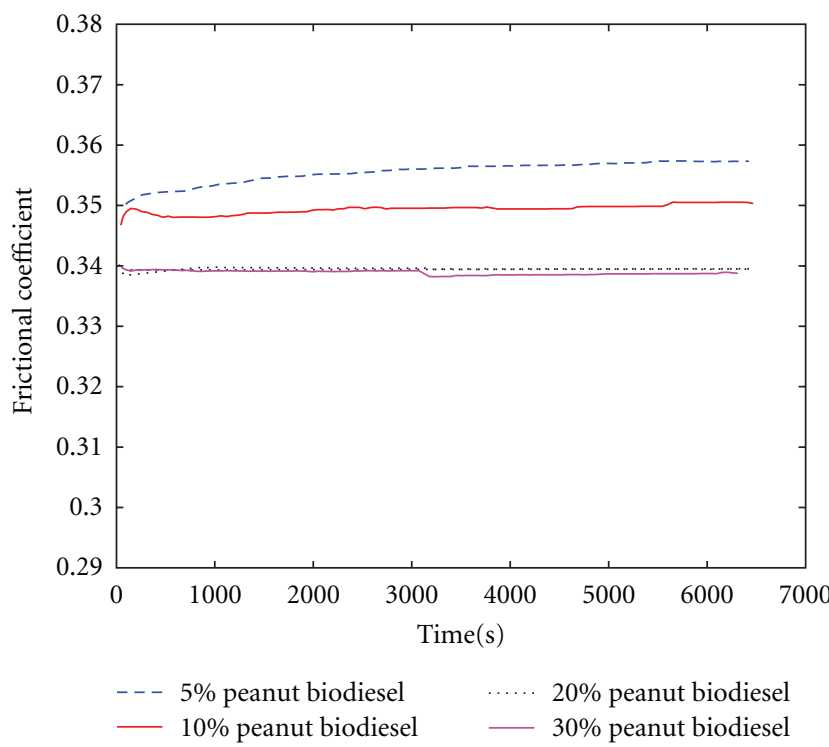

FIGURE 5: Friction force versus time for peanut oil biodiesel diluted engine oil mixtures. 


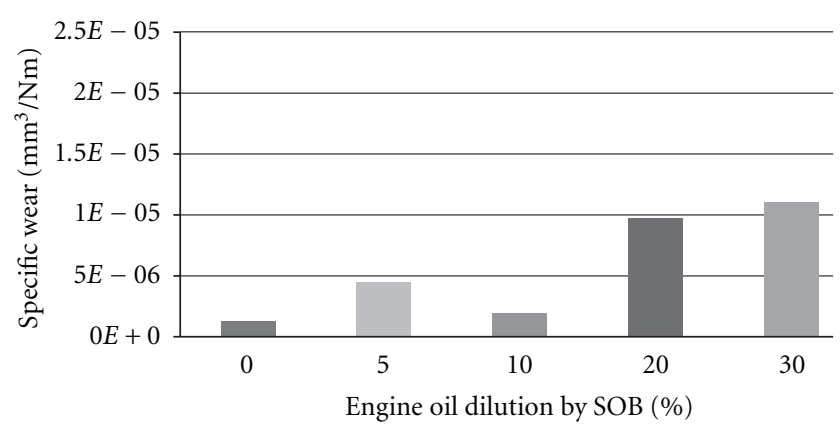

FIgure 6: Specific wear for soybean-oil biodiesel (SOB) diluted engine oil mixtures.

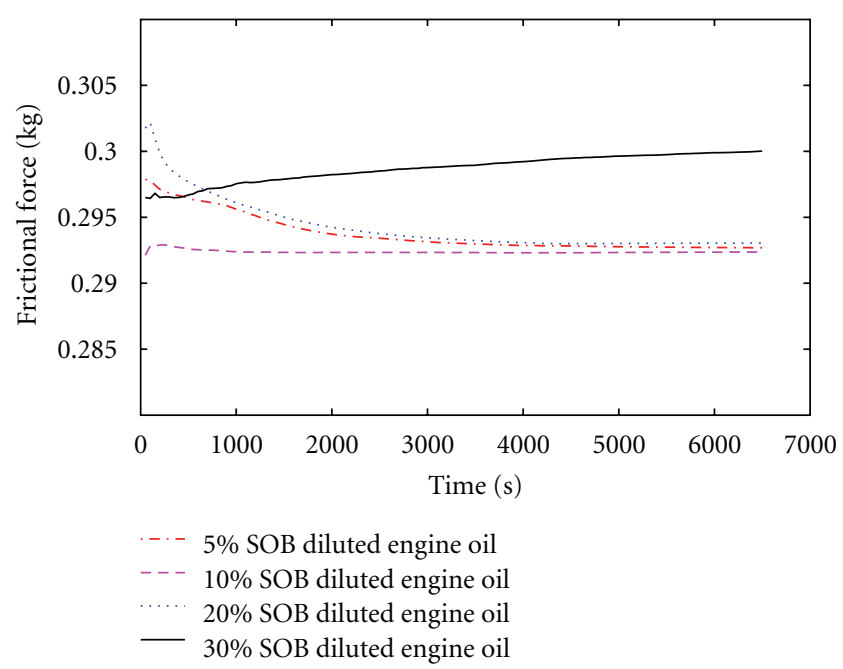

Figure 7: Friction force versus time for soybean-oil biodiesel diluted engine oil mixtures.

same and seemingly constant during the experiments (each equivalent to 1 hour 51 minutes, or 6667 seconds). But for the $30 \%$ dilution a substantial increment of friction force, but seemingly tending towards a constant value, was observed from the start of the experiment run.

3.4. Results for Mixtures of Chicken Fat Biodiesel Diluted Engine Oil. The employed engine oil $(15 \mathrm{~W}-40)$ was diluted with the chicken fat-oil biodiesel at 5\%,10\%,20\%, and 30\% volume ratios. Figure 8 presents specific wear measurements for these four mixtures and pure engine oil as reference. While pure engine mineral oil $(0 \%)$ shows the lowest wear for the tested conditions, for the $5 \%$ and $10 \%$ dilutions wear is not substantially larger than that reference, but the $20 \%$ chicken-fat-oil-biodiesel mixture shows the maximum wear for this biodiesel mixture in the tested dilution interval.

The in-process friction force measurement is presented in Figure 9, which shows that friction force tends to a constant value after a transient of about or more than 4,000 seconds. After that, and for all the four dilution percentages, frictional force did not significantly increased during test time, and seemingly tends to constant values. This indicates that no lubrication failure would have occurred in the $1000 \mathrm{~m}$

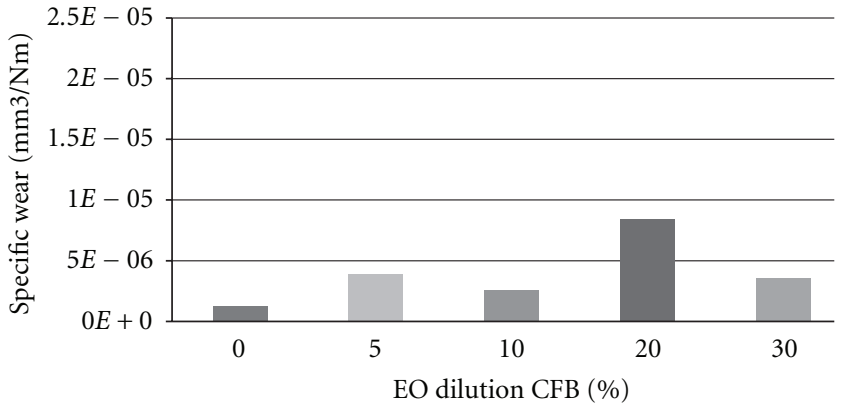

Figure 8: Specific wear for chicken-fat biodiesel (CFB) diluted engine oil mixtures.

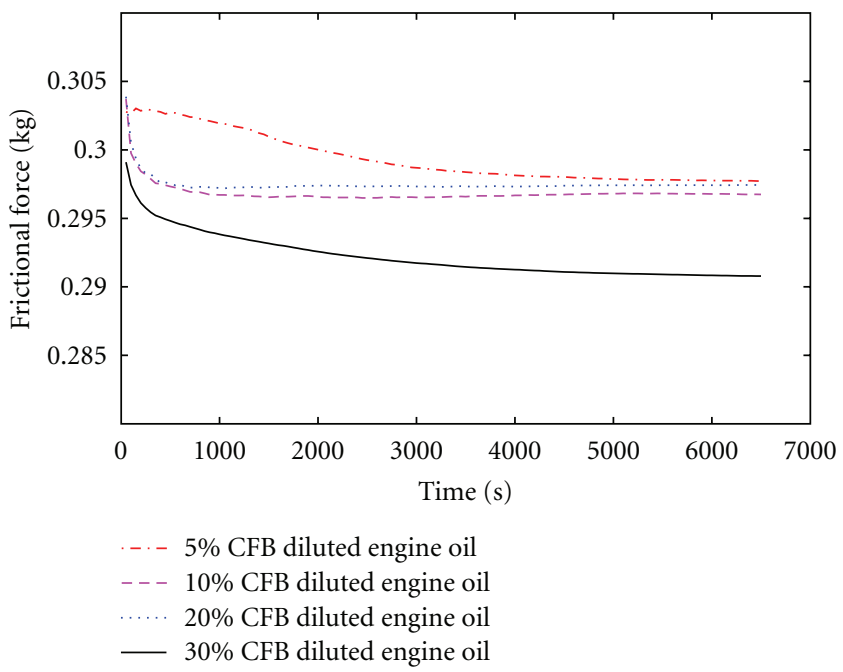

Figure 9: Friction force versus time for chicken fat-oil biodiesel diluted engine oil mixtures.

sliding distance contact (equivalent to 1 hour 51 minutes, or 6667 seconds).

3.5. Comparison to Reference Mixtures of Fossil Diesel on Mineral Oils and Discussion. The employed engine oil (15W40) also was diluted with fossil diesel, as a set of reference mixtures, for the same $5 \%, 10 \%, 20 \%$, and $30 \%$ volume ratios, and pin-on-disk tests were carried out for each mixtures for the same test conditions than those of biodiesel mixtures. Figure 10 presents the summary of measured wear for all mixtures of the four tested biodiesel on SAE 15W-40 oil, as compared with those from fossil diesel in oil mixtures

The wear values reported in Figure 10 for the four biodiesels show that any degree of mineral oil dilution by the tested biodiesels reduces the wear protection performance of the engine oil in the investigated intervals, even at small amounts, such as the tested 5\% dilution. However, the measured levels of wear for all four biodiesel mixtures, are not substantially different than corresponding wear values for mixtures of fossil-diesel in same SAE15W-40 oil (also shown for comparison in Figure 10), or about twice as much for the $20 \%$ of canola-oil biodiesel mixture. Is it important to note that for the highest tested dilution of 


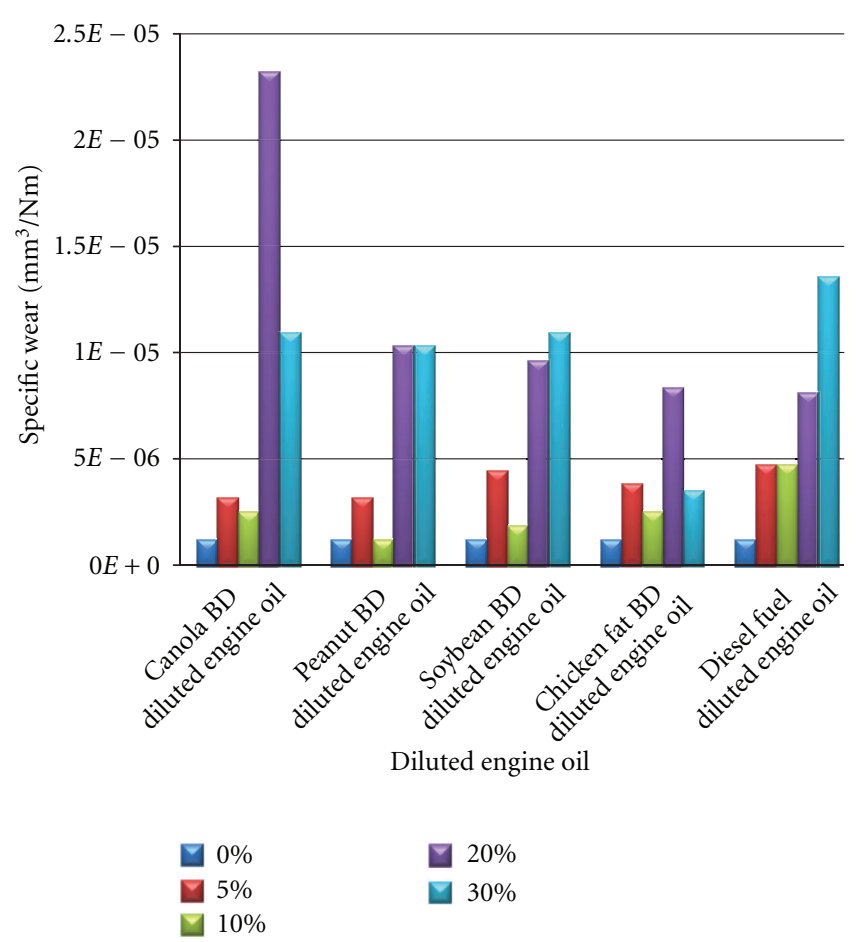

Figure 10: Specific wear for mixtures of all four types of biodiesel (BD) and fossil diesel diluting engine oil.

$30 \%$, all four biodiesel mixtures yielded lower wear than the corresponding wear measured for $30 \%$ dilution by fossil diesel.

Although peanut-oil biodiesel and chicken-fat biodiesel produced specific wear relatively lower than those for the two other tested biodiesel mixtures, biodiesel wear values were up to five-times greater than those for pure $15 \mathrm{~W}-40$ engine oil under the same experimental conditions and run parameters (shown as the wear values for $0 \%$ contamination in each of the specific wear plots).

The overall performance of the tested animal fat (chicken fat) biodiesel diluted engine oil was better than those of vegetable feedstock biodiesel, particularly for 20\% and 30\% volume dilutions. Chicken fat biodiesel typically contains around $25 \%$ of palmitic acid, being that fatty acid content is higher than those typical for the other tested (vegetable feedstock) biodiesels [14, 15]. Animal fat biodiesel also contains smaller amount of linoleic acid than those of vegetable feedstock biodiesel $[14,15]$. The overall results in this study suggest that higher amounts of palmitic acid and lower amounts of linoleic acid may play a role in the reduced wear observed for chicken fat biodiesel dilutions of mineral oil. Among the tested vegetable feedstock biodiesels, peanut oil biodiesel yielded a lower surface wear for $5 \%$ and $10 \%$ contamination in mineral oil, this may be due to the typically lower linoleic acid content of peanut-oil biodiesel, as compared to that for soybean-oil and canola-oil biodiesel mixtures.

All wear results for the $10 \%$ of biodiesel dilution are lower than those for $5 \%$, but also smaller than values measured for the 20\% dilutions (which produced the highest wear for the tested interval). These results could be explained on two competing effects from the addition of biodiesel: while small amounts of biodiesel may add some lubricity to the mineral oil (as for 10\% biodiesel as compared to same percentage of fossil diesel), for larger $20 \%$ the interactions of the biodiesel fatty acids with the engine oil antiwear additives may starve the contact surface of such additives, in particular for ZDDP (zinc dialkyl dithio phosphate). Typically ZDDP bonds to the lubricated metal surfaces to form a protective layer against wear, but the polar components in biodiesels (e.g., the fatty acid methyl esters) may also attract the ZDDP molecule [18], and they could lead to additive starvation. Literature research $[7,8]$ showed that biodiesel fuel dilution had a negative impact on engine oil performance because methyl esters in biodiesel partially degraded and interacted with the ZDDP antiwear additives, and that biodiesel in the engine oil caused enhanced oxidation, which led to acid components and a reduction in total base number.

In-process friction force for all tested biodiesel-in-oil mixtures in the tested percentage intervals showed an initial transient followed by a seemingly constant friction force. But observed transients varied between short ones, as for canola-oil- and peanut-oil-derived biodiesel mixtures, to significantly longer ones, as for soybean-oil and chickenfat mixtures. Friction forces for canola-oil and peanut-oil biodiesel mixtures also were larger than those for soybean and chicken fat biodiesels. The effects of different biodiesel fractions on the viscosity of the mixtures and on the formation of protective soap layers by additives (while eventually affected by additive interactions with the biodiesel fatty acids) may explain these friction force differences and transients [6], but such hypotheses were not investigated in this research work.

\section{Conclusions}

This research work showed the feasibility of employing a pin-on-disk tribometer for testing wear and friction force changes on selected metal surfaces while lubricated with mixtures of biodiesel in engine oil. Biodiesels from four types of feedstock were tested: canola, peanut and soybean oil biodiesels, and a chicken fat biodiesel. Engine oil (15W40 ) was diluted with $5 \%, 10 \%, 20 \%$, and $30 \%$ of the four different biodiesels, and also with same volume percentages of conventional fossil diesel; pure engine oil (15W-40) also was tested under same conditions as reference.

Results of this work suggest that any degree of mineraloil dilution by the tested biodiesels can reduce the wear protection properties of the engine oil. But while this research and most available literature show that lubricant oil dilution by biodiesel has a negative impact on engine oil wear protection, such impact is not substantially different than the one observed in this work for the same percentages of dilution of mineral oil by fossil diesel (which naturally occurs in fossil-fueled diesel engines).

The wear-protection performance of the tested animal fat feedstock (e.g., chicken fat) biodiesel when diluting engine oil was found better than those for the tested vegetable 
biodiesel dilutions; these results suggest that higher fractions of palmitic acid and smaller ones of linoleic acid components in the biodiesels may play a role on reducing surface wear when they contaminate mineral oil. Interactions of these fatty acids with oil antiwear additives may be the key for understanding this wear behavior. In particular, biodiesel interactions with ZDDP are of interest, because the polar components in biodiesel (e.g., in fatty acid methyl ester) can also attract the ZDDP molecule and therefore reduce the additive antiwear performance. Oxidation stability also could be a factor when mixing biodiesel with engine oil [18]. The authors are planning further research work to explore these hypotheses, as part of a renewable energy multidisciplinary approach on biofuels and biolubes at Georgia Southern University.

\section{Acknowledgments}

This paper was supported by a Faculty Research Committee grant, and a graduate student assistantship from Georgia Southern University. The authors also thank the Renewable Energy and Engines Laboratory in Georgia Southern University for their generous support within this collaborative multidisciplinary research on biofuels.

\section{References}

[1] M. J. Ramos and C. M. Fernández, "Influence of fatty acid composition of raw materials on biodiesel properties," Bioresource Technology, vol. 100, no. 1, pp. 161-168, 2009.

[2] F. Gili, A. Igartua, R. Luther, and M. Woydt, "The Impact of Biofuels on Engine oil performance," in Proceedings of the 17th International Colloquium Tribology, Technische Akademie Esslingen, Ostfildern, Germany, January 2010.

[3] H. L. Fang, D. W. Shawn, S. Yamaguchi, and M. Boons, "Biodiesel impact on wear protection of engine oils," in Proceedings of the Powertrain \& Fluid Systems Conference, Chicago, III, USA, October 2007, SAE paper 2007-01-4141.

[4] M. W. Sulek, A. Kulczycki, and A. Malysa, "Assessment of lubricity of compositions of fuel oil with biocomponents derived from rape-seed," Wear, vol. 268, no. 1, pp. 104-108, 2010.

[5] M. Jech, T. Wopelka, and F. Franek, "Lubricating performance of mixtures of blo-diesel and mineral diesel investigated in a model tribometer with radioactive isotopes," in Proceedings of the STLE/ASME International Joint Tribology Conference (IJTC '08), pp. 753-755, Miami, Fla, USA, October 2008.

[6] A. K. Agarwal, "Experimental investigations of the effect of biodiesel utilization on lubricating oil tribology in diesel engines," Proceedings of the Institution of Mechanical Engineers Part D, vol. 219, no. 5, pp. 703-713, 2005.

[7] M. J. Thornton, T. Alleman, J. Luecke, and R. McCormick, "Impact of biodiesel fuel oil dilution on light -duty diesel engine operation," in Proceedings of the SAE International Power Train, Fuels and Lubricants Meeting, Florence, Italy, June 2009.

[8] S. A. G. Watson and V. W. Wong, "The effects of fuel dilution with biodiesel and low sulfur diesel on lubricant acidity, oxidation and corrosion - A bench scale study with CJ4 and CI-4+ lubricants," in Proceedings of the STLE/ASME International Joint Tribology Conference (IJTC '08), pp. 233 235, Miami, Fla, USA, October 2008.
[9] A. K. van Helden, R. J. van der Meer, J. J. van Staaden, and E. van Gelderen, "Dynamic friction in cam/tappet lubrication," SAE Technical Paper Series 850441, 1985.

[10] M. E. Crane and R. A. Meyer, "Process to predict friction in an automotive valve train," SAE Technical Paper Series 901728, 1990.

[11] Y. Wakuri, M. Soejima, Y. Ejima, T. Hamatake, and T. Kitahara, "Studies on friction characteristics of reciprocating engines," SAE Technical Paper Series 952471, 1995.

[12] J. K. Choi, B. S. Min, and D. Y. Oh, "A study on the friction characteristics of engine bearing and cam/tappet contacts from the measurement of temperature and oil film thickness," SAE Technical Paper Series 952472, 1995.

[13] J. Bijwe, A. K. Agarwal, and A. Sharma, "Assessment in an automotive engine of lubricity of biodiesel blends in reciprocating wear mode," in Proceedings of the SAE Powertrain and Fluid Systems Conference and Exhibition, Tampa, Fla, USA, October 2004, SAE paper 2004-01-3068.

[14] V. Soloiu, J. Lewis, and A. Covington, "Oleic methyl ester investigations in an indirect injection diesel engine-stage one: combustion investigations," SAE International Journal of Fuels and Lubricants, vol. 4, no. 1, pp. 85-75, 2011.

[15] V. Soloiu, D. Nelson, and A. Covington, "Investigations of a poultry fat-fatty acid methyl ester in a triple vortex separate combustion chamber diesel engine-stage one: combustion investigations," in Proceedings of the SAE World Congress, Detroit, Mich, USA, 2011, SAE 2011-01-1188.

[16] Mobil Delvac Elite 15W-40, 2010, http://www.mobil.com/ USA-english/Lubes/PDS/GLXXENCVLMOMobil_Delvac_ Elite_15W-40.aspx.

[17] R. Kholi and K. L. Mittal, Developments in Surface Contamination and Cleaning, Fundamentals and Applied Aspects, William Andrew, 2008.

[18] C. R. McKinley and J. H. Lumkes, "Quantitative evaluation of an on-highway trucking fleet to compare \#2ULSD and B20 fuels and their impact on overall fleet performance," Applied Engineering in Agriculture, vol. 25, no. 3, pp. 335-346, 2009.

[19] S. M. Shanta, Investigations of the tribological effects of engine oil dilution by vegetable and animal fat feedstock biodiesel on selected surfaces, M.S. thesis, Department of Mechanical and Electrical Engineering, Georgia Southern University, Statesboro, Ga, USA, 2011. 

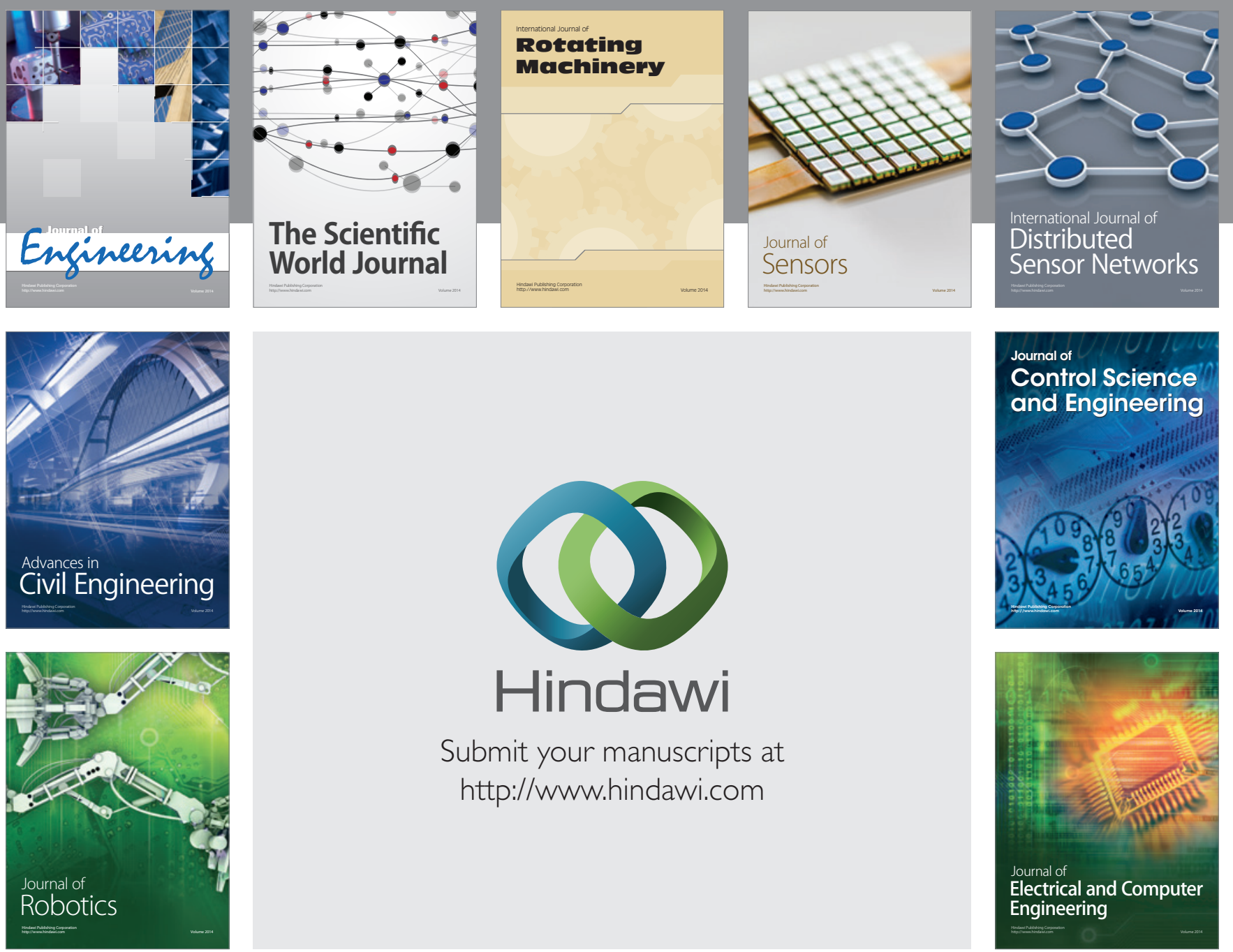

Submit your manuscripts at

http://www.hindawi.com
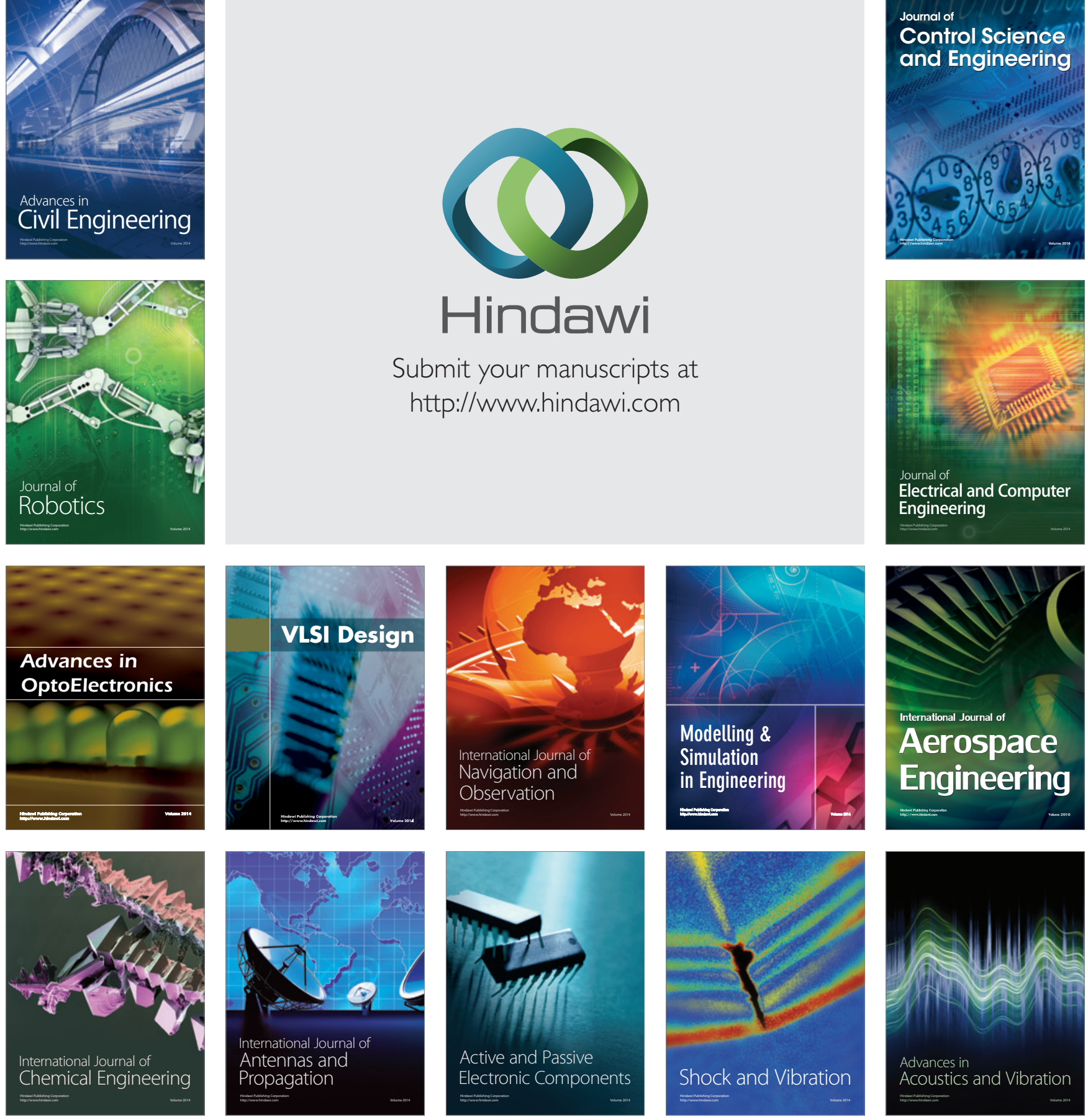